\title{
A National Study of Chronic Disease Prevalence and Access to Care in Uninsured U.S. Adults
}

Andrew P. Wilper, MD, MPH; Steffie Woolhandler, MD, MPH; Karen E. Lasser, MD, MPH; Danny McCormick, MD, MPH; David H. Bor, MD; and David U. Himmelstein, MD

Background: No recent national studies have assessed chronic illness prevalence or access to care among persons without insurance in the United States.

Objective: To compare reports of chronic conditions and access to care among U.S. adults, by self-reported insurance status.

Design: Population-based survey.

Setting: National Health and Nutritional Examination Survey (19992004).

Participants: 12486 patients age 18 to 64 years.

Measurements: Estimates of national rates of cardiovascular disease, hypertension, diabetes, hypercholesterolemia, active asthma or chronic obstructive pulmonary disease, previous cancer, and measures of access to care.

Results: On the basis of National Health and Nutrition Examination Survey (1999-2004) responses, an estimated 11.4 million $(95 \% \mathrm{Cl}$, 9.8 million to 13.0 million) working-age Americans with chronic conditions were uninsured, including $16.1 \%(\mathrm{Cl}, 12.6 \%$ to $19.6 \%)$ of the 7.8 million with cardiovascular disease, $15.5 \%(\mathrm{Cl}, 13.4 \%$ to $17.6 \%)$ of the 38.2 million with hypertension, and $16.6 \%(\mathrm{Cl}$, $13.2 \%$ to $20.0 \%$ ) of the 8.5 million with diabetes. After the authors controlled for age, sex, and race or ethnicity, chronically ill patients without insurance were more likely than those with coverage to have not visited a health professional $(22.6 \%$ vs. $6.2 \%)$ and to not have a standard site for care $(26.1 \%$ vs. $6.2 \%)$ but more likely to identify their standard site for care as an emergency department (7.1\% vs. $1.1 \%)$ ( $P<0.001$ for all comparisons).

Limitation: The study was cross-sectional and used self-reported insurance and disease status.

Conclusion: Millions of U.S. working-age adults with chronic conditions do not have insurance and have poorer access to medical care than their insured counterparts.

Ann Intern Med. 2008;149:170-176.

www.annals.org
$\mathrm{T}$ he number of Americans without insurance increased from 31 million in 1987 to 47 million in $2006(1,2)$. Policymakers, including President George W. Bush, have cited the youthfulness and presumed health of those without insurance (3-5), and some have argued that the predicament of uninsured persons is often voluntary and rarely consequential (6).

Chronic illnesses, such as diabetes mellitus, coronary artery disease, and hypertension, are highly prevalent in the United States. Modern therapies for these conditions extend life and minimize disabling complications (7-11).

Fragmentary data suggest that lack of health insurance may worsen care of chronic illness. A medically indigent population in California had deterioration in blood pressure control and self-reported health status after their Medicaid coverage was discontinued (12). Persons without health insurance may be more likely to skip medications, use the emergency department, and be hospitalized (13,

See also:

Print

Editors' Notes . . . . . . . . . . . . . . . . . . . . . . . . . 171

Editorial comment. . . . . . . . . . . . . . . . . . . . 206

Web-Only

Appendix Table

Conversion of graphics into slides
14). Outcomes are worse among uninsured patients with breast cancer (15). Among a cohort of persons age 55 to 64 years, not having coverage increased death rates and the cost of care after age 65 years $(16,17)$. Lack of coverage has been correlated with undiagnosed and uncontrolled hypertension, elevated cholesterol levels, stroke, and death (18, 19). However, to our knowledge, no study has drawn a more complete picture of the burden of chronic physical illness in the uninsured population in the United States as a whole.

We analyzed interview data from a nationally representative sample of working-age Americans to explore the relationship of common chronic illnesses to health insurance and access to care.

\section{Methods}

\section{Data Source}

To evaluate individuals age 18 to 64 years in the United States, we used 6 years of data (1999-2004) from the continuous NHANES (National Health and Nutrition Examination Survey), which is conducted during 2-year intervals. The National Center for Health Statistics conducts NHANES, which is designed to assess the health and nutrition status of the noninstitutionalized U.S. population. The survey is conducted in English and Spanish and includes interviews, physical examinations, and laboratory testing. Because almost all persons older than age 64 years

170|C 2008 American College of Physicians 


\section{Context}

Although many Americans lack health insurance, some policymakers claim that persons without insurance are largely healthy. However, the rates of chronic illness among those without insurance have not been well documented.

\section{Contribution}

By using data from the National Health and Nutrition Examination Survey (1999-2004), this study estimates that more than 11 million working-age Americans with cardiovascular disease, hypertension, diabetes, dyslipidemia, obstructive lung disease, or previous cancer do not have health insurance. Individuals without health insurance were more likely than those with insurance to report problems with access to health care.

\section{Implication}

Many uninsured Americans have health conditions that require ongoing care.

- The Editors

are eligible for Medicare, we excluded participants in this age group.

We compiled 3 cycles of data in order to bolster sample size. We created a final 6-year weight by assigning twothirds weight to individuals surveyed during 1999 to 2002 and by assigning one-third weight to individuals surveyed from 2003 to 2004 (20). The weights used in NHANES adjust for the complex survey design, nonresponse, oversampling of low-income individuals and minorities, and poststratification to yield nationally representative estimates. All analyses account for the survey's complex design (that is, weights, stratification, and clustering).

Staff members for NHANES interview respondents in their homes about demographic variables (including health insurance), medical conditions, and 3 measures of access to care, which include having a place to go when sick or in need of medical advice, having a standard site of medical care, and the number of visits to a physician or health care professional in the past 12 months. Details about the NHANES methods are available elsewhere (21).

From 1999 to 2004, NHANES selected 38086 persons for the sample; 31126 of those participated in interviews. At the time of the interview, 12712 were age 18 to 64 years and 12486 reported health insurance status (Figure).

We included conditions in our study on the basis of 2 criteria: a diagnosis that would probably require a need for medical care follow-up and robust data on the condition (collected by NHANES). We used questionnaire data to classify participants as having cardiovascular disease (CVD), obstructive pulmonary disease, or cancer. We considered a person to have CVD if they reported coronary heart disease, angina or angina pectoris, heart attack, heart failure, or stroke. We classified participants confirming active asthma, chronic bronchitis, or a history of emphysema as having active obstructive pulmonary disease. We considered participants to have had previous cancer if they reported any previous cancer (other than nonmelanoma skin cancer).

To establish rates of diabetes, hypertension, and hypercholesterolemia, we combined questionnaire data on previous diagnoses with that on current medication use. For instance, we considered participants to have diabetes if a physician had informed them that they had "sugar diabetes" or if they were receiving insulin or an oral hypoglycemic drug.

Similarly, we defined participants as hypertensive if they reported being told by a medical professional that they had high blood pressure or if they were taking an antihypertensive medication. We identified antihypertensive drugs by using the U.S. Food and Drug Administration National Drug Code Directory Formulation Data File and Drug Class Data File for 1999 to 2002 and the Lexicon Plus proprietary database (Cerner Multum, Denver, Colorado) for 2003 to 2004. A 5-member panel of boardcertified internists reviewed a list of antihypertensive medications and determined which drugs were usually prescribed for hypertension (for example, hydrochlorothiazide) and others that have several uses (for example, diltiazem). We did a sensitivity analysis defining hypertension with and without inclusion of the multiuse drugs and ultimately excluded these drugs because they had little effect on our results.

We defined participants as hypercholesterolemic if they reported that a health professional had informed them

\section{Figure. Study flow diagram.}

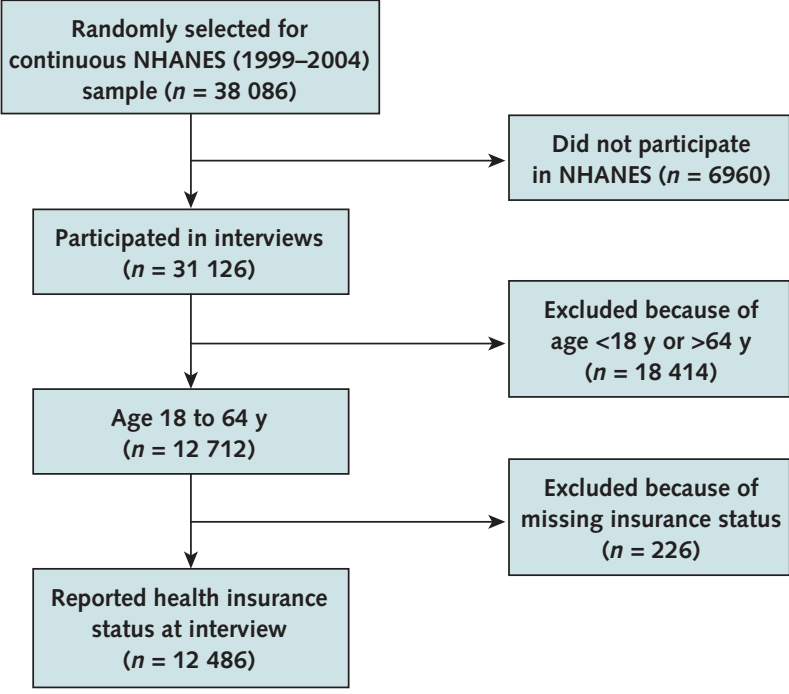

NHANES $=$ National Health and Nutrition Examination Survey. 5 August 2008 $\mid$ Annals of Internal Medicine $\mid$ Volume 149 • Number $3 \mid \mathbf{1 7 1}$ 
that they had high cholesterol or they were taking a statin, a bile acid sequestrant, or ezetimibe.

Next, we counted the number of chronic conditions that each respondent had and determined the proportion who reported having no health insurance. The NHANES determined participants' self-reported insurance status on the basis of a single question: "Are you covered by health insurance or some other kind of health care plan? Include health insurance obtained through employment or purchased directly as well as government programs like Medicare and Medicaid that provide medical care or help pay medical bills." We excluded nonrespondents $(1.8 \%$ of nonelderly adults). Individuals reporting insurance coverage who answered questions about insurance type-including private insurance, Medicare, Medicaid or Children's Health Insurance Program, other government insurance, or any single service plan (that is, paying for only 1 type of service, such as nursing home or dental care) —and not having insurance in the past year. The Appendix Table (available at www.annals.org) shows a complete list of the survey questions.

\section{Statistical Analysis}

We used NHANES interview weights to produce national estimates. To account for the complex sample design, we used SAS software, version 9.1 (SAS Institute, Cary, North Carolina); PROC SURVEYFREQ (SAS Institute) to generate percentages and chi-square tests; and the PROC RLOGIST procedure (SUDAAN, version 9.0.3, Research Triangle Institute, Research Triangle Park, North Carolina) for multiple logistic regression.

We stratified participants with each chronic medical condition by the presence of self-reported health insurance. By using logistic regression, we first tested the validity of combining several survey years by examining whether year of participation predicted health insurance status. We evaluated the relationship between having any of the 6 chronic conditions (CVD, hypertension, obstructive pulmonary disease, diabetes, previous cancer, or hypercholesterolemia) and the likelihood of having health insurance, controlling for age, sex, and race or ethnicity (defined as non-Hispanic white, non-Hispanic black, Hispanic, and other). In subsidiary analyses, we controlled for annual household income. Income data were missing for $8.7 \%$ of participants; these individuals were less likely to have insurance than those who reported income ( $25.7 \%$ vs. $20.8 \%$; chi-square, 9.95; $P=0.002$ ).

We then used multiple logistic regression to produce predictive margins adjusted for age, sex, and race or ethnicity to determine whether health insurance status was associated with differences in measures of access to care. In a subsidiary analysis, we controlled for income. Predictive margins are a type of direct standardization that average predicted values from logistic regression models across the covariate distribution in the sample. We analyzed subsamples to produce predictive margins, such that these re- sults reflect only the subsamples studied (that is, they compare access measures only among those with CVD). Estimates in the insured group could be interpreted as the average predicted outcome if every individual in the sample had insurance; estimates in the uninsured group could be interpreted as the average predicted outcome if every individual in the sample did not have insurance (22).

\section{Role of the Funding Source}

This study was funded by a Health Service Administration National Research Service Award and approved by the institutional review board at Cambridge Health Alliance. The funding source had no role in the design, conduct, or presentation of this study.

\section{RESULTS}

Demographic Characteristics and Health Insurance Status

A total of 12486 nonelderly adults who participated in NHANES also reported their health insurance status. Of those interviewed, $50.9 \%$ (95\% CI, $50.0 \%$ to $51.9 \%)$ were women, $68.4 \%(\mathrm{CI}, 65.0 \%$, to $71.9 \%)$ were nonHispanic white, $11.6 \%$ (CI, 9.5\% to $13.7 \%$ ) were nonHispanic black, $8.3 \%$ (CI, 6.5\% to $10.1 \%$ ) were Mexican American, $6.2 \%$ (CI, $3.9 \%$ to $8.4 \%$ ) were other Hispanic, and $5.4 \%$ (CI, $4.4 \%$ to $6.5 \%$ ) were other race or ethnicity (Table 1).

On the basis of the responses from NHANES, we estimate that $20.8 \%$ of nonelderly adults in the United States did not have insurance (36.4 million [CI, 40.0 million to 33.1 million]), a figure consistent with estimates from the U.S. Census Bureau (23-25). Among those reporting insurance coverage, $87.9 \%(\mathrm{CI}, 86.7 \%$ to $89.1 \%$ ) were covered by private insurance, $3.2 \%(\mathrm{CI}, 2.4 \%$ to $3.9 \%$ ) by Medicare, $6.7 \%$ (CI, $5.8 \%$ to $7.7 \%$ ) by Medicaid or Children's Health Insurance Program, and 4.9\% (CI, $4.0 \%$ to $5.9 \%$ ) by other government insurance.

\section{Prevalence of Chronic Conditions}

An estimated 11.4 million working-age Americans with chronic conditions were uninsured, including $16.1 \%$ of the 7.8 million with CVD, $15.5 \%$ of the 38.2 million with hypertension, and more than $16.6 \%$ of the 8.5 million with diabetes. Among persons without insurance, $31.3 \%$ (CI, $28.7 \%$ to $34.0 \%$ ) had at least 1 of the 6 chronic illnesses, a rate less than that of those with insurance ( $45.4 \%$ [CI, $43.6 \%$ to $47.1 \%])$, presumably reflecting the lower average age of persons without insurance. After adjusting for sex, age, and race or ethnicity, this difference narrowed substantially to $38.0 \%$ (CI, $35.0 \%$ to 41.1 ) versus $43.5 \%$ (CI, $41.5 \%$ to $45.5 \%$ ) (Table 2 ).

\section{Comorbid Conditions}

Comorbid conditions were common. We estimate that nearly 1 in 5 nonelderly adults (17.5\%) had a history of at least 2 chronic conditions, whereas $6.0 \%$ had 3 or more (Table 3). 
National Study of Disease Prevalence and Access to Care in U.S. Adults $\mid$ ARTICLE

Table 1. Demographic Characteristics and Self-Reported Insurance Status of U.S. Adults Age 18 to 64 Years*

\begin{tabular}{|c|c|c|c|}
\hline \multirow[t]{2}{*}{ Characteristic } & \multicolumn{2}{|c|}{ Millions of Persons $(95 \% \mathrm{Cl})$} & \multirow{2}{*}{$\begin{array}{l}\text { Uninsured Persons } \\
(95 \% \mathrm{Cl}), \%\end{array}$} \\
\hline & Insured & Uninsured & \\
\hline Men & $64.4(60.2-68.7)$ & $19.8(18.0-21.5)$ & $23.1(21.5-24.6)$ \\
\hline Women & $71.1(66.5-75.5)$ & $16.6(15.0-18.3)$ & $18.7(17.1-20.3)$ \\
\hline \multicolumn{4}{|l|}{ Age } \\
\hline $18-24 y$ & $18.0(15.8-20.2)$ & $8.7(7.5-9.9)$ & $31.8(28.8-34.8)$ \\
\hline $25-34 y$ & $28.1(25.7-30.4)$ & $9.9(8.7-11.2)$ & 25.7 (23.4-28.0) \\
\hline $35-44$ y & $34.0(30.6-37.3)$ & $9.0(7.9-10.2)$ & $20.7(18.0-23.4)$ \\
\hline $45-54 y$ & $34.2(30.9-37.5)$ & $5.9(5.2-6.6)$ & $14.5(12.7-16.3)$ \\
\hline $55-64 y$ & $21.2(18.6-23.7)$ & $2.8(2.1-3.6)$ & $11.6(8.6-14.7)$ \\
\hline \multicolumn{4}{|l|}{ Race or ethnicity } \\
\hline White, non-Hispanic & 99.2 (89.9-108.4) & $18.7(15.7-21.8)$ & $15.7(14.0-17.4)$ \\
\hline Black, non-Hispanic & $14.9(12.5-17.3)$ & $5.0(4.0-6.0)$ & $24.6(22.6-26.5)$ \\
\hline Mexican American & $7.2(5.7-8.7)$ & $7.1(5.6-8.5)$ & $48.5(44.5-52.6)$ \\
\hline Other Hispanic & $7.0(4.4-9.6)$ & $3.5(2.1-5.0)$ & $32.9(27.8-38.0)$ \\
\hline Other & $7.1(5.7-8.5)$ & $2.1(1.4-2.8)$ & $21.9(16.5-27.2)$ \\
\hline Total & $135.4(127.2-143.7)$ & $36.4(33.1-40.0)$ & $20.8(19.4-22.3)$ \\
\hline
\end{tabular}

* Data estimated from the National Health and Nutrition Examination Survey (1999-2004).

\section{Likelihood of Having Insurance}

After age, race or ethnicity, sex, and income were controlled for, persons with a chronic illness were statistically significantly more likely than other Americans to have health insurance $(81.6 \%$ [CI, $79.6 \%$ to $83.6 \%)$ vs. 77.1 [75.1\% to $79.1 \%$ ]; $P<0.001)$.

\section{National Estimates of Access to Care and 12-Month Utilization for Chronically III Americans}

After sex, race or ethnicity, and age were controlled for, chronically ill persons without insurance were more likely than those with insurance to have not visited a health professional in the past year $(22.6 \%$ vs. $6.2 \%)$ and to not have a standard site for care $(26.1 \%$ vs. $6.2 \%)$ but more likely to identify a standard site for care as an emergency department $(7.1 \%$ vs. $1.1 \%)$. Further adjustment for income did not alter these findings. The remaining results in Table 4 estimate access measures for the subgroup in each row.

\section{DISCUSSION}

Chronic illness is common among persons without insurance. We identified individuals without insurance who had a previous diagnosis of cardiovascular disease (1.3 million), hypertension (5.9 million), diabetes ( 1.4 million), hypercholesterolemia (4.0 million), active asthma or chronic obstructive pulmonary disease (3.5 million), and previous cancer ( 1.1 million). We estimate that nearly one third of nonelderly U.S. adults without insurance (that is, 11.4 million individuals) had at least 1 chronic condition. These findings counter notions that persons without insurance are a largely healthy population with little need for ongoing medical care.

On the basis of NHANES responses, access to health care seems to be systematically worse for persons without insurance than for those with coverage. Chronically ill persons without insurance are less likely to have visited a physician in the past 12 months or have a standard source of care but are more likely to report using an emergency de-

\section{Table 2. Prevalence of 6 Chronic Conditions, by Self-Reported Insurance Status, among U.S. Adults Age 18 to 64 Years*}

\begin{tabular}{|c|c|c|c|}
\hline \multirow[t]{2}{*}{ Condition } & \multicolumn{2}{|c|}{ Millions of Persons $(95 \% \mathrm{Cl})$} & \multirow{2}{*}{$\begin{array}{l}\text { Uninsured Persons } \\
(95 \% \mathrm{Cl}), \%\end{array}$} \\
\hline & Insured & Uninsured & \\
\hline Cardiovascular disease & $6.5(5.3-7.7)$ & $1.3(0.9-1.7)$ & $16.1(12.6-19.6)$ \\
\hline Hypertensiont & $32.3(29.1-35.5)$ & $5.9(4.9-6.9)$ & $15.5(13.4-17.6)$ \\
\hline Diabetes mellitust & $7.1(6.1-8.1)$ & $1.4(1.0-1.8)$ & $16.6(13.2-20.0)$ \\
\hline Hypercholesterolemiat & $32.9(29.9-35.9)$ & $4.0(3.3-4.8)$ & $11.9(9.3-12.6)$ \\
\hline Asthma or COPD & $14.4(12.7-16.1)$ & $3.5(2.7-4.3)$ & $19.3(16.0-22.3)$ \\
\hline Previous cancerł & $5.9(4.9-6.8)$ & $1.1(0.8-1.4)$ & $15.4(11.5-19.3)$ \\
\hline Any of the above & $61.4(56.5-66.3)$ & $11.4(9.8-13.0)$ & $15.6(14.0-17.3)$ \\
\hline
\end{tabular}

COPD = chronic obstructive pulmonary disease.

* Data estimated from the National Health and Nutrition Examination Survey (1999-2004).

† Includes previous diagnosis or taking a prescription medication in the past month for the condition.

₹ Excludes nonmelanoma skin cancer. 
National Study of Disease Prevalence and Access to Care in U.S. Adults $\mid$ ARTICLE

\begin{tabular}{|c|c|c|c|}
\hline \multirow[t]{2}{*}{ Characteristic } & \multicolumn{2}{|c|}{ Millions of Persons $(95 \% \mathrm{Cl})$} & \multirow{2}{*}{$\begin{array}{l}\text { Uninsured Persons } \\
(95 \% \mathrm{Cl}), \%\end{array}$} \\
\hline & Insured & Uninsured & \\
\hline Men & $64.4(60.2-68.7)$ & $19.8(18.0-21.5)$ & $23.1(21.5-24.6)$ \\
\hline Women & $71.1(66.5-75.5)$ & $16.6(15.0-18.3)$ & $18.7(17.1-20.3)$ \\
\hline \multicolumn{4}{|l|}{ Age } \\
\hline $18-24 y$ & $18.0(15.8-20.2)$ & $8.7(7.5-9.9)$ & $31.8(28.8-34.8)$ \\
\hline $25-34 y$ & $28.1(25.7-30.4)$ & $9.9(8.7-11.2)$ & $25.7(23.4-28.0)$ \\
\hline $35-44 y$ & $34.0(30.6-37.3)$ & $9.0(7.9-10.2)$ & $20.7(18.0-23.4)$ \\
\hline $45-54$ y & $34.2(30.9-37.5)$ & $5.9(5.2-6.6)$ & $14.5(12.7-16.3)$ \\
\hline $55-64 y$ & $21.2(18.6-23.7)$ & $2.8(2.1-3.6)$ & $11.6(8.6-14.7)$ \\
\hline \multicolumn{4}{|l|}{ Race or ethnicity } \\
\hline White, non-Hispanic & $99.2(89.9-108.4)$ & $18.7(15.7-21.8)$ & $15.7(14.0-17.4)$ \\
\hline Black, non-Hispanic & $14.9(12.5-17.3)$ & $5.0(4.0-6.0)$ & $24.6(22.6-26.5)$ \\
\hline Mexican American & $7.2(5.7-8.7)$ & $7.1(5.6-8.5)$ & $48.5(44.5-52.6)$ \\
\hline Other Hispanic & $7.0(4.4-9.6)$ & $3.5(2.1-5.0)$ & $32.9(27.8-38.0)$ \\
\hline Other & $7.1(5.7-8.5)$ & $2.1(1.4-2.8)$ & $21.9(16.5-27.2)$ \\
\hline Total & $135.4(127.2-143.7)$ & $36.4(33.1-40.0)$ & $20.8(19.4-22.3)$ \\
\hline
\end{tabular}

* Data estimated from the National Health and Nutrition Examination Survey (1999-2004).

\section{Likelihood of Having Insurance}

After age, race or ethnicity, sex, and income were controlled for, persons with a chronic illness were statistically significantly more likely than other Americans to have health insurance $(81.6 \%$ [CI, $79.6 \%$ to $83.6 \%)$ vs. 77.1 [75.1\% to $79.1 \%] ; P<0.001)$.

\section{National Estimates of Access to Care and 12-Month} Utilization for Chronically III Americans

After sex, race or ethnicity, and age were controlled for, chronically ill persons without insurance were more likely than those with insurance to have not visited a health professional in the past year $(6.2 \%$ vs. $22.6 \%)$ and to not have a standard site for care $(6.2 \%$ vs. $26.1 \%)$ but more likely to identify a standard site for care as an emergency department (7.1\% vs. $1.1 \%)$. Further adjustment for income did not alter these findings. The remaining results in Table 4 estimate access measures for the subgroup in each row.

\section{DISCUSSION}

Chronic illness is common among persons without insurance. We identified individuals without insurance who had a previous diagnosis of cardiovascular disease (1.3 million), hypertension (5.9 million), diabetes (1.4 million), hypercholesterolemia (4.0 million), active asthma or chronic obstructive pulmonary disease (3.5 million), and previous cancer ( 1.1 million). We estimate that nearly one third of nonelderly U.S. adults without insurance (that is, 11.4 million individuals) had at least 1 chronic condition. These findings counter notions that persons without insurance are a largely healthy population with little need for ongoing medical care.

On the basis of NHANES responses, access to health care seems to be systematically worse for persons without insurance than for those with coverage. Chronically ill persons without insurance are less likely to have visited a physician in the past 12 months or have a standard source of care but are more likely to report using an emergency de-

Table 2. Prevalence of 6 Chronic Conditions, by Self-Reported Insurance Status, among U.S. Adults Age 18 to 64 Years*

\begin{tabular}{|c|c|c|c|}
\hline \multirow[t]{2}{*}{ Condition } & \multicolumn{2}{|c|}{ Millions of Persons $(95 \% \mathrm{Cl})$} & \multirow{2}{*}{$\begin{array}{l}\text { Uninsured Persons } \\
(95 \% \mathrm{Cl}), \%\end{array}$} \\
\hline & Insured & Uninsured & \\
\hline Cardiovascular disease & $6.5(5.3-7.7)$ & $1.3(0.9-1.7)$ & $16.1(12.6-19.6)$ \\
\hline Hypertensiont & $32.3(29.1-35.5)$ & $5.9(4.9-6.9)$ & $15.5(13.4-17.6)$ \\
\hline Diabetes mellitust & $7.1(6.1-8.1)$ & $1.4(1.0-1.8)$ & $16.6(13.2-20.0)$ \\
\hline Hypercholesterolemiat & $32.9(29.9-35.9)$ & $4.0(3.3-4.8)$ & $11.9(9.3-12.6)$ \\
\hline Asthma or COPD & $14.4(12.7-16.1)$ & $3.5(2.7-4.3)$ & $19.3(16.0-22.3)$ \\
\hline Previous cancer‡ & $5.9(4.9-6.8)$ & $1.1(0.8-1.4)$ & $15.4(11.5-19.3)$ \\
\hline Any of the above & $61.4(56.5-66.3)$ & $11.4(9.8-13.0)$ & $15.6(14.0-17.3)$ \\
\hline
\end{tabular}

COPD = chronic obstructive pulmonary disease.

* Data estimated from the National Health and Nutrition Examination Survey (1999-2004).

† Includes previous diagnosis or taking a prescription medication in the past month for the condition. ‡ Excludes nonmelanoma skin cancer.

www.annals.org
\begin{tabular}{|l|c|c|c|c|c|c|c|}
\hline rich4/zai-aim/zai-aim/zai01508/zai2668d08g & springj & $\mathrm{S}=18$ & $7 / 28 / 08$ & 15:01 & 4/Color Figure(s): 1 & Art: M08-0160 \\
\hline
\end{tabular}


Table 3. Prevalence of Any of 6 Chronic Conditions and Self-Reported Insurance Status among U.S Adults Age 18 to 64 Years*

\begin{tabular}{lcl}
$\begin{array}{l}\text { Number } \\
\text { of Chronic } \\
\text { Conditions }\end{array}$ & $\begin{array}{l}\text { All Persons } \\
(95 \% \mathrm{Cl}), \%\end{array}$ & $\begin{array}{l}\text { Uninsured Persons } \\
(95 \% \mathrm{Cl}), \%\end{array}$ \\
\hline 0 & $57.6(56.0-59.3)$ & $25.2(23.6-26.9)$ \\
\hline 1 & $42.4(40.7-44.1)$ & $15.7(14.0-17.3)$ \\
\hline 2 & $17.5(16.1-18.9)$ & $14.4(12.1-16.6)$ \\
\hline 3 & $6.0(5.4-6.7)$ & $11.5(8.5-14.6)$
\end{tabular}

* Data estimated from the National Health and Nutrition Examination Survey (1999-2004). Chronic conditions were previous diagnosis of cardiovascular disease; active asthma or chronic obstructive pulmonary disease; previous cancer (excluding nonmelanoma skin cancer); and previous diagnosis of or current medication use for hypertension, diabetes mellitus, or hypercholesterolemia.

partment as a standard site for care. Even after sociodemographic confounders were controlled for, persons without insurance were 4 to 6 times more likely to have each of these 3 access problems. Many of these individuals probably cannot obtain standard medical care to control chronic conditions because they do not have health insurance.

Why do so many working-age Americans lack health insurance? The decreasing size of many U.S. companies, the increasing role of service sector jobs, and the decline in manufacturing jobs have steadily eroded employer-sponsored coverage. Increasing premiums discourage companies from offering coverage; discourage uptake among workers required to pay a share of premium costs; and make insur- ance particularly unaffordable for self-employed persons, especially if they have a chronic illness (26).

Persons without insurance are typically less affluent than those who have it and face substantially higher costs in both absolute and relative terms when using health care. Low-cost or free services, if available, may be at locations, times, or settings that discourage uptake. These barriers lead to diminished access to care that negatively affects health-related outcomes, an effect that may be pronounced among individuals with chronic disease (27).

A MEDLINE search of studies published in English until January 2008 shows that many researchers have analyzed the health effects of not having insurance (12-19). To our knowledge, only 1 study has examined the burden of chronic conditions among the uninsured population as a whole (28). Compared with data from the Behavior Risk Factor Surveillance System, our results suggest an increase in the proportion of patients who had hypertension $(\geq 34 \%)$, diabetes $(\geq 51 \%)$, and hypercholesterolemia $(\geq 49 \%)$ and were uninsured from 1997 to 1998 . However, these increases should be interpreted with caution, given the different survey methodologies.

Our study has several limitations. We could not verify self-reported insurance status. However, our estimate of those without insurance is virtually identical to that generated from the Current Population Survey, the standard source for rates of coverage in the United States. The NHANES' exclusion of individuals who do not speak English or Spanish may lead to an underestimate of the num-

Table 4. Indicators of Poor Access to Care among U.S. Adults Age 18 to 64 Years, and Predictive Margins*

Chronic Condition

Predictive Margin, \%

\begin{tabular}{|c|c|c|c|c|c|c|c|c|c|}
\hline & \multicolumn{2}{|c|}{$\begin{array}{l}\text { No Standard Site for Care } \\
\text { When Sick }(95 \% \mathrm{Cl})\end{array}$} & \multirow[t]{2}{*}{$\begin{array}{l}P \\
\text { Value }\end{array}$} & \multicolumn{2}{|c|}{$\begin{array}{l}\text { Use Emergency Department } \\
\text { Most Often }(95 \% \mathrm{Cl})\end{array}$} & \multirow[t]{2}{*}{$\begin{array}{l}P \\
\text { Value }\end{array}$} & \multicolumn{2}{|c|}{$\begin{array}{l}\text { No Visits to a Health } \\
\text { Professional in Past } 12 \text { mo } \\
(95 \% \mathrm{Cl})\end{array}$} & \multirow[t]{2}{*}{$\begin{array}{l}P \\
\text { Value }\end{array}$} \\
\hline & Insured & Uninsured & & Insured & Uninsured & & Insured & Uninsured & \\
\hline $\begin{array}{l}\text { Cardiovascular disease } \\
\quad(n=585)\end{array}$ & $3.5(0.0-6.9)$ & $17.4(9.4-25.4)$ & 0.004 & $3.1(2.1-4.1)$ & $15.3(3.3-27.3)$ & 0.053 & $3.0(1.0-5.0)$ & $23.4(13.4-33.4)$ & $<0.001$ \\
\hline $\begin{array}{l}\text { Hypertension } \\
\qquad(n=2729) \dagger\end{array}$ & $4.6(3.6-5.6)$ & $21.9(17.9-25.9)$ & $<0.001$ & $1.3(0.3-2.3)$ & $6.5(3.5-9.5)$ & $<0.001$ & $4.7(3.7-5.7)$ & $19.7(14.7-24.7)$ & $<0.001$ \\
\hline $\begin{array}{l}\text { Hypercholesterolemia } \\
\qquad(n=2326) \dagger\end{array}$ & $5.5(4.5-6.5)$ & $24.4(18.4-30.4)$ & $<0.001$ & $0.5(0.1-0.9)$ & $6.5(1.5-11.5)$ & 0.013 & $5.9(4.9-6.9)$ & $24.2(18.2-30.2)$ & $<0.001$ \\
\hline $\begin{array}{l}\text { Asthma or COPD } \\
\quad(n=1170)\end{array}$ & $5.8(3.8-7.8)$ & $26.1(20.1-32.1)$ & $<0.001$ & $1.2(0.2-2.2)$ & $10.8(5.8-15.8)$ & $<0.001$ & $4.8(2.8-6.8)$ & $19.2(13.2-25.2)$ & $<0.001$ \\
\hline $\begin{array}{l}\text { Previous cancer } \\
\qquad(n=413) \ddagger\end{array}$ & $7.4(3.4-11.4)$ & $13.9(7.9-19.9)$ & 0.044 & $1.4(0.2-2.6)$ & $7.8(0.0-15.8)$ & 0.11 & $5.4(2.4-8.4)$ & $17.0(8.0-26.0)$ & 0.025 \\
\hline $\begin{array}{l}\text { Any of the above } \\
\text { chronic conditions } \\
(n=4946)\end{array}$ & $6.2(5.2-7.2)$ & $26.1(23.1-29.1)$ & $<0.001$ & $1.1(0.1-2.1)$ & $7.1(5.1-9.1)$ & $<0.001$ & $6.2(5.2-7.2)$ & $22.6(19.6-25.6)$ & $<0.001$ \\
\hline
\end{tabular}

COPD $=$ chronic obstructive pulmonary disease.

* Data estimated from the National Health and Nutrition Examination Survey (1999-2004). Predictive margins were produced by using only the disease subsample from each row and were adjusted for age, sex, and race or ethnicity. Predictive margins can be interpreted as follows: If all persons with cardiovascular disease in the sample were insured, the average of the predicted outcome of not having a standard site for care when sick would be $3.5 \%$. If they were not insured, the average of the predicted outcome of not having a standard site for care when sick would be $17.4 \%$.

t Includes previous diagnosis or taking a prescription medication in the past month for the condition.

\# Excludes nonmelanoma skin cancer.

$\mathbf{1 7 4} \mid 5$ August 2008 $\mid$ Annals of Internal Medicine $\mid$ Volume $149 \bullet$ Number 3 
ber of persons without insurance. Because NHANES does not review medical records, recall bias may cause understatement of the overall prevalence of diagnosed disease. Persons without insurance may be less likely to recall a previous diagnosis because of longer intervals between their visits with health care professionals. However, in our experience, most cognitively intact patients react strongly to new diagnoses, such as diabetes, and are likely to remember them.

Our results probably underestimate the health problems of persons without insurance because those without insurance are less likely to be aware of their illnesses (18). We could not analyze depression or other chronic mental health conditions because NHANES does not query participants about them. Finally, we could not include health insurance plan details (that is, cost sharing) and duration of coverage.

Given the limited access to care among those without insurance, undiagnosed conditions in this population may be common. Future research should evaluate rates of undiagnosed illness and disease control among persons without insurance. Research should also determine whether extending health insurance to chronically ill persons reduces use of the emergency department as a standard site for care. Most important, research and advocacy should focus on ways to expand health insurance coverage.

Substantial proportions of persons with and without insurance have a history of at least 1 of the conditions identified in our study. Among chronically ill persons, lack of health insurance is strongly associated with poor measures of access to care. For some of the 11.4 million uninsured Americans with serious chronic conditions, access to care seems to be unobtainable; many may face early disability and death as a result.

Treatment of the chronic conditions we studied has become both the standard of care $(10,29-31)$ and a national priority (32). The benefits of treatment are so clear that studies evaluating new treatments of these conditions are ethically bound to provide control participants with standard therapies. The same ethical consideration has not been extended to those without insurance.

From Cambridge Health Alliance/Harvard Medical School, Cambridge, Massachusetts.

Acknowledgment: The authors thank John Z. Ayanian, MD, and Sarah Hollopeter, MD, for their comments on an earlier draft of the manuscript, and Amy Cohen, Manager of Instructional Computing, Harvard School of Public Health, for her help with statistical software.

Grant Support: By Health Resources and Service Administration National Research Service Award 5T32 HP110011 (Dr. Wilper).

Potential Financial Conflicts of Interest: None disclosed.

Reproducible Research Statement: Study protocol: The NHANES methodology is available from the Centers for Disease Control and Pre- vention (www.cdc.gov/nchs/about/major/nhanes/datalink.htm.) Statistical code and data set: Available from Dr. Wilper (e-mail, awilper@hsph .harvard.edu).

Requests for Single Reprints: Andrew P. Wilper, MD, Cambridge Health Alliance/Harvard Medical School, 1493 Cambridge Street, Cambridge, MA 02139; e-mail, awilper@hsph.harvard.edu.

Current author addresses and author contributions are available at www .annals.org.

\section{References}

1. U.S. Census Bureau. Current Population Survey, 1988 to 2006 Annual Social and Economic Supplements. Historical Health Insurance Tables. Accessed at www.census.gov/hhes/www/hlthins/historic/hlthin05/hihistt7.html on 20 December 2007.

2. U.S. Census Bureau. Current Population Survey, 2000 to 2007 Annual Social and Economic Supplements. Historical Health Insurance Tables. Accessed at www.census.gov/hhes/www/hlthins/historic/hihistt2.html on 20 December 2007.

3. Economic Report of the President. Transmitted to Congress February 2004. Chapter 10, page 197. Accessed at www.gpoaccess.gov/usbudget/fy05/pdf 12004_erp.pdf on 20 December 2007.

4. Cannon MF. "Cover the Uninsured Week"-With Honesty. Washington, DC: Cato Institute; 2004. Accessed at www.cato.org/pub_display.php?pub _id $=2657$ on 15 August 2007.

5. Westerfield DL. Insuring the Uninsured Through Association Health Plans. Washington, DC: National Center for Policy Analysis; 2003. Accessed at www .ncpa.org/pub/st/st259/ on 8 August 2007.

6. President Bush Visits Cleveland, Ohio. Accessed at www.whitehouse.gov/news /releases/2007/07/20070710-6.html on 8 August 2007.

7. The effect of intensive treatment of diabetes on the development and progression of long-term complications in insulin-dependent diabetes mellitus. The Diabetes Control and Complications Trial Research Group. N Engl J Med. 1993; 329:977-86. [PMID: 8366922]

8. Mortality findings for stepped-care and referred-care participants in the hypertension detection and follow-up program, stratified by other risk factors. The Hypertension Detection and Follow-up Program Cooperative Research Group. Prev Med. 1985;14:312-35. [PMID: 2865725]

9. Stratton IM, Adler AI, Neil HA, Matthews DR, Manley SE, Cull CA, et al. Association of glycaemia with macrovascular and microvascular complications of type 2 diabetes (UKPDS 35): prospective observational study. BMJ. 2000;321: 405-12. [PMID: 10938048]

10. Capewell S, Morrison CE, McMurray JJ. Contribution of modern cardiovascular treatment and risk factor changes to the decline in coronary heart disease mortality in Scotland between 1975 and 1994. Heart. 1999;81:380-6. [PMID: 10092564]

11. Rahimi AR, Spertus JA, Reid KJ, Bernheim SM, Krumholz HM. Financial barriers to health care and outcomes after acute myocardial infarction. JAMA. 2007;297:1063-72. [PMID: 17356027]

12. Lurie N, Ward NB, Shapiro MF, Gallego C, Vaghaiwalla R, Brook RH. Termination of Medi-Cal benefits. A follow-up study one year later. N Engl J Med. 1986;314:1266-8. [PMID: 3517642]

13. Collins S. Gaps in Health Insurance: An All-American Problem. In: Findings From the Commonwealth Fund Biennial Health Insurance Survey; 2006. Accessed at www.cmwf.org/usr_doc/Collins_gapshltins_920.pdf on 20 July 2007. 14. Weissman JS, Gatsonis C, Epstein AM. Rates of avoidable hospitalization by insurance status in Massachusetts and Maryland. JAMA. 1992;268:2388-94. [PMID: 1404795]

15. Ayanian JZ, Kohler BA, Abe T, Epstein AM. The relation between health insurance coverage and clinical outcomes among women with breast cancer. $\mathrm{N}$ Engl J Med. 1993;329:326-31. [PMID: 8321261]

16. McWilliams JM, Zaslavsky AM, Meara E, Ayanian JZ. Health insurance coverage and mortality among the near-elderly. Health Aff (Millwood). 2004;23: 223-33. [PMID: 15318584]

17. McWilliams JM, Meara E, Zaslavsky AM, Ayanian JZ. Use of health services by previously uninsured Medicare beneficiaries. N Engl J Med. 2007;357: 
ARTICLE $\mid$ National Study of Disease Prevalence and Access to Care in U.S. Adults

143-53. [PMID: 17625126]

18. Ayanian JZ, Zaslavsky AM, Weissman JS, Schneider EC, Ginsburg JA. Undiagnosed hypertension and hypercholesterolemia among uninsured and insured adults in the Third National Health and Nutrition Examination Survey. Am J Public Health. 2003;93:2051-4. [PMID: 14652333]

19. Fowler-Brown A, Corbie-Smith G, Garrett J, Lurie N. Risk of cardiovascular events and death—-does insurance matter? J Gen Intern Med. 2007;22:502-7. [PMID: 17372800]

20. Analytic and Reporting Guidelines. The National Health and Nutrition Examination Survey (NHANES). 2006. Accessed at www.cdc.gov/nchs/data Inhanes/nhanes_03_04/nhanes_analytic_guidelines_dec_2005.pdf on 21 March 2008.

21. National Center for Health Statistics, Centers for Disease Control and Prevention (CDC). Survey operations manuals, brochures, and consent documents: 1999-current NHANES. Accessed at www.cdc.gov/nchs/about/major /nhanes/currentnhanes.htm on 2 April 2008.

22. Korn EL, Graubard BI. Analysis of Health Surveys. (Wiley Series in Probability and Statistics). New York: Wiley; 1999.

23. U.S. Census Bureau, Center for Population Statistics. Health Insurance Coverage Status and Type of Coverage by Selected Characteristics 2000. Accessed at http://pubdb3.census.gov/macro/032001/health/h01_001.htm on 29 June 2007.

24. U.S. Census Bureau, Center for Population Statistics. Health Insurance Coverage Status and Type of Coverage by Selected Characteristics 2002. Accessed at http://pubdb3.census.gov/macro/032003/health/h01_001.htm on 29 June
2007.

25. U.S. Census Bureau, Center for Population Statistics. Health Insurance Coverage Status and Type of Coverage by Selected Characteristics 2004. Accessed at http://pubdb3.census.gov/macro/032005/health/h01_001.htm on 29 June 2007.

26. Swartz K. Reinsuring Health: Why More Middle-class People Are Uninsured and What Government Can Do. New York: Sage; 2006.

27. Institute of Medicine. Care Without Coverage Too Little, Too Late. Washington, DC: National Academy Pr; 2002.

28. Ayanian JZ, Weissman JS, Schneider EC, Ginsburg JA, Zaslavsky AM. Unmet health needs of uninsured adults in the United States. JAMA. 2000;284: 2061-9. [PMID: 11042754]

29. Baigent C, Keech A, Kearney PM, Blackwell L, Buck G, Pollicino C, et al. Cholesterol Treatment Trialists' (CTT) Collaborators. Efficacy and safety of cholesterol-lowering treatment: prospective meta-analysis of data from 90,056 participants in 14 randomised trials of statins. Lancet. 2005;366:1267-78. [PMID: 16214597]

30. Suissa S, Ernst P, Benayoun S, Baltzan M, Cai B. Low-dose inhaled corticosteroids and the prevention of death from asthma. N Engl J Med. 2000;343: 332-6. [PMID: 10922423]

31. Sin DD, McAlister FA, Man SF, Anthonisen NR. Contemporary management of chronic obstructive pulmonary disease: scientific review. JAMA. 2003; 290:2301-12. [PMID: 14600189]

32. Geyman JP. Disease management: panacea, another false hope, or something in between? Ann Fam Med. 2007;5:257-60. [PMID: 17548854]

\section{CME CREDIT}

Readers can get CME credit for the following: 1) questions from the ACP's Medical Knowledge Self-Assessment Program (MKSAP) related to In the Clinic articles that are published in the first issue of every month, and 2) designated articles in each issue. To access CME questions, click on the CME option under an article's title on the table of contents at www.annals.org. Subscribers may take the tests free of charge. For a nominal fee, nonsubscribers can purchase tokens electronically that enable them to take the CME quizzes.

Reviewers who provide timely, high-quality reviews also may get CME credit. 


\section{Annals of Internal Medicine}

Current Author Addresses: Drs. Wilper, Woolhandler, Lasser, McCormick, Bor, and Himmelstein: Cambridge Health Alliance/Harvard Medical School, 1493 Cambridge Street, Cambridge, MA 02144.

Author Contributions: Conception and design: A.P. Wilper, S. Woolhandler, K.E. Lasser, D. McCormick, D.H. Bor, D.U. Himmelstein. Analysis and interpretation of the data: A.P. Wilper, S. Woolhandler, K.E. Lasser, D. McCormick, D.U. Himmelstein.

Drafting of the article: A.P. Wilper, S. Woolhandler.

Critical revision of the article for important intellectual content: A.P. Wilper, S. Woolhandler, K.E. Lasser, D. McCormick, D.H. Bor, D.U. Himmelstein.

Final approval of the article: A.P. Wilper, S. Woolhandler, K.E. Lasser, D. McCormick, D.H. Bor, D.U. Himmelstein.

Statistical expertise: A.P. Wilper, S. Woolhandler, D.U. Himmelstein.
Obtaining of funding: D.H. Bor.

Administrative, technical, or logistic support: A.P. Wilper. Collection and assembly of data: A.P. Wilper.

33. National Health and Nutrition Examination Survey Codebook for Data Production (1999-2000). The Medical Conditions Section of the SP Questionnaire (MCQ). Person Level Data. Accessed at www.cdc.gov/nchs/data/nhanes /frequency/mcq.pdf on 11 June 2008.

34. National Health and Nutrition Examination Survey Codebook for Data Production (2001-2002). The Medical Conditions Section of the SP Questionnaire (MCQ_B). Person Level Data. Accessed at www.cdc.gov/nchs/data/nhanes /nhanes_01_02/mcq_b_cbk.pdf on 11 June 2008.

35. National Health and Nutrition Examination Survey Codebook for Data Production (2003-2004). Documentation, Codebook, and Frequencies MEC Questionnaire Component: Medical Conditions Questionnaire Data. Accessed at www.cdc.gov/nchs/data/nhanes/nhanes_03_04/mcq_c.pdf on 11 June 2008.

\section{Appendix Table. Survey Questions Used to Establish Study Variables*}

\section{Variable}

Insurance status

Insured or uninsured

Type of insurance

Uninsured in past year

Chronic conditions

Cardiovascular disease or stroke

Hypertension

Diabetes mellitus

Hypercholesterolemia

Active asthma or chronic obstructive pulmonary disease

\section{Sample Question}

Are you covered by health insurance or some other kind of health care plan? Include health insurance obtained through employment or purchased directly, as well as government programs like Medicare and Medicaid that provide medical care or help pay medical bills.

Are you covered by private insurance?

Are you covered by Medicare?

Are you covered by Medicaid or CHIP?

Are you covered by other government insurance?

Are you covered by single service plan?

In the past 12 months, was there any time when you did not have any health insurance coverage?

Has a doctor or other health professional ever told you that you had congestive heart failure?

Has a doctor or other health professional ever told you that you had coronary heart disease?

Has a doctor or other health professional ever told you that you had angina or angina pectoris?

Has a doctor or other health professional ever told you that you had heart attack?

Has a doctor or other health professional ever told you that you had a stroke?

Have you ever been told by a doctor or other health professional that you had hypertension, also called high blood pressure?

Other than during pregnancy, have you ever been told by a doctor or health professional that you have diabetes or sugar diabetes?

Have you ever been told by a doctor or other health professional that your blood cholesterol level was high?

(Among those with asthma) Do you still have asthma?

Has a doctor or other health professional ever told you that you had emphysema?

Has a doctor or other health professional ever told you that you had chronic bronchitis?

CHIP $=$ Children's Health Insurance Program.

* Data from National Health and Nutrition Examination Survey Codebook for Data Production (33-35). 